\title{
Describing Teachers' Pedagogic Content Knowledge about Reasoning Development and Students' Reasoning Test
}

\author{
Rendi Restiana Sukardi \\ Student of Science Education Program \\ UniversitasPendidikan Indonesia \\ Bandung, Indonesia \\ rendisukardi@ymail.comm
}

\author{
Wahyu Sopandi \\ Chemistry Education Department \\ UniversitasPendidikan Indonesia \\ Bandung, Indonesia \\ wsopandi@upi.edu
}

\author{
Ari Widodo \\ Biology Education Department \\ UniversitasPendidikan Indonesia \\ Bandung, Indonesia \\ widodo@upi.edu
}

One of the strategies that can help science teachers to Abstract- Pedagogic Content Knowledge (PCK) is very important for teachers because it shows teacher understanding of science knowledge and pedagogical knowledge. PCK covers the knowledge of content and pedagogy such as teaching knowledge (the subject knowledge and their belief in that, and how to teach it), curriculum knowledge (what and when to teach), assessment knowledge (why, what, and how to assess), the knowledge of students' comprehension toward the subject, and instructional knowledge. To assess teacher PCK we used an instrument called content representation (CoRe).Although CoRe has shown effectiveness in assesssing teacher PCK, however, it does not include reasoning. Learning is considered meaningful when learning activities involve student' to think and to reason. Thus, we need an instrument which enables us to assess teacher's PCK about reasoning and students' reasoning skill. Therefore, for the purpose of the study the researchers modified CoRe to include reasoning. Samples of this study are 8 teachers and 42 students. The modified CoRe measured teacher's formulation of learning goals, content to be taught, pedagogical aspects in teaching particular material, assessment of students learning, and the methods in developing students' reasoning skill. Based on their responses to CoRe, teacher PCK are classified into pre PCK, growing PCK, and maturing PCK. Paper and pencil tests are administered to students to measure their reasoning skills. The instruments consist of thwelve questions related to pollution, i.e. water pollution, air pollution, and land pollution. Test

Keywords-CoRe, Pedagogic Content Knowledge, Reasoning

\section{INTRODUCTION}

A competent science teacher has to have high pedagogical competence and knowledge about science. Such knowledge is important for teachers to design appropriate lessons. In fact, based on the studies for the past 20 years, it can be seen that there are many people graduated from education department who are incapable and have insufficient knowledge to apply the pedagogical knowledge in their teaching process [11].Some teachers do not have sufficient pedagogical knowledge that they need intensive professional development improve their teaching practice is by improving their PCK and the implementation of PCK into teaching. PCK becomes the competence which has to be acquired by teachers because it is the core of the delivering some particular materialsmethod[8]. Improving PCK helps teachers to conduct science class effectively[4].

As science teachers, we could find new ways in planning and evaluating our work related to our teaching needs. PCK offers the lens to see how to become a science teacher,which can be implemented and used in meaningful ways in teacher preparation programs[16].Kind[21]identified three common factors that appear to contribute to the development of early career teacher, i.e. teacher's pedagogical content knowledge; classroom experience (which some studies have pointed out the significant changes occurring in the early months and years of working as a teacher); and the possession of emotional attributes such as good levels of personal self confidence, and provision of supportive working atmospheres in which collaboration is encouraged. By analyzing PCK, we could knowwhich position of a teacher, whether beginner or expert level.

PCK of experienced teacher is the result of the knowledge transformation, including the knowledge of materials such as teaching knowledge (the subject knowledge and their belief in that, and how to teach it), curriculum knowledge (what and when to teach), assessment knowledge (why, what, and how to assess), the knowledge of students' comprehension toward the subject, and instructional knowledge [21]. To measure teacher's PCK, there area number of strategies and instruments available. One of the mostly used instruments is Content Representation (CoRe) by Loughran, Berry, and Mulhall [15]. The result of those CoRe elements showed the effectiveness of learning activity with particular goals which are aimed to be achieved in science class.CoRe is a kind of questionaire aimed to investigate aspects of PCK. When teacher do not have sufficient knowledge related to the 
questions,the possibility of answering CoRe questions was low or they could not answer those [1] [4] [7] [11][12][16] [21].

The core of learning science is the activity that can involve students in their cognitive process which allows them to think and to reason.One of important goals to be achieved in science class is developing students' reasoning skills. Reasoning is a process about a particular topic that related to drawing conclusion logically, systematically, and structurally. Reasoning skill has the great impact to thinking skill on inquiry activity, students' academic achievement, and conceptual change[14].

McNeill and Krajcik[20] argue that reasoning involves constructing claim (statement or conclusion that shows question or problem), providing evidence (data, theory, principal, or something that support claim) and constructing argumentation (reason that build relation between claim and evidence). Santrock[10] argues that reasoning is a part of logical thinking using inductive and deductive skill to form a conclusion. Vigotsky explains that students' reasoning usuallyappears when they are arguing with others[5]. Their reasoning process can be identified by its output: an argument. Argumentation can be in a form of discussion activity between teacher-student and student-student. It is science learning about investigation of statement and evidence logically [17]. Students who lack of reasoning skill are incapable in delivering their views of something. When they argue, they will think hard to analyze and to evaluate the evidence in order to support their statement. According to Kurniadi et al[13], students who have not reached a certain level in reasoning, are not able to create an argument. Students produce and evaluate the reason which can convince others. Students also have to use strong evidences to make their arguments acceptable by people. Thus, it is needed to have an instrument which is able to access students' reasoning skill. The instrument is reasoning test that contains problem and needs solutions as answer. The topic is environmental pollution. We chose this topic because this topic became socio-scientific issue, so people with different background of education could understand this issue.

The research about PCK and reasoning skill has been conducted by many researchers, but the research aimed to measure thePCK related to developing reasoning hasn't been conducted yet. This is very important to do because teacher's PCK has the main role to shape student with good reasoning skill. Teacher with good PCKknow whow to develop students' reasoning skill using appropriate methods. Thus, we need an instrument which is able to describe those aspects. The instrument should be valid because it can measure the data accurately. Therefore, validating instrument is important.

Based on the explanation above, the researchers are going to investigate; how is effectiveness of the newly developed instruments in measuring teachers' PCK about students' reasoning development and how is the profile of students' reasoning skill.

\section{THEORETICAL FRAMEWORK}

\section{A. Pedagogic Content Knowledge}

In this study, the instrument which was applied to assess teachers' PCK is a modified CoRe originally developed by Loghran, Berry, and Mulhall [14], and William et al[21]. The instrument consists of questions related to teacher's competency in designing their goals, the concept which will be applied, pedagogical aspects used in teaching the particular material, evaluation element, and the methods in developing students' reasoning skill.

\section{B. Reasoning Skill}

Students' reasoning skills were analyzed based on the completeness of students' argumentation as obtained through reasoning test. Argumentation is a conversation that involves reasoning process and critical thinking. Students' skills were classified into level 1 until level 5[5]. These are the description:

TABLE I. REASONING SKILL LEVEL BASED ON ARGUMENTS COMPLETENESS

\begin{tabular}{|l|l|}
\hline Level & \multicolumn{1}{|c|}{ Argument Components } \\
\hline 1 & claim vs counter claimor claim vs claim, \\
\hline 2 & claim vs claim with data, warrant, orbackingwithout rebuttal \\
\hline 3 & $\begin{array}{l}\text { Someclaim orcounter-claims with data, warrant, backingor } \\
\text { qualifierwith weakrebuttal }\end{array}$ \\
\hline 4 & $\begin{array}{l}\text { claim, data, warrant, backing, qualifier, with a very clearrebuttal } \\
\text { claim, data, warrant, backing, qualifier, completed with more } \\
\text { than onerebuttal. }\end{array}$ \\
\hline
\end{tabular}

\section{Environmental Pollution}

We divided the topic of environmental pollution into 3 ideas. They are water pollution, air pollution, and land pollution. Students should analyze the pollution, its effect, and the solution for those problems. As prescribed the the curriculum, upon completing the lessons should be able to describe pollution and its effect for human life. Therefore, the assessment focuses of these competencies.

\section{RESEARCH METHOD}

The research site was in Bandung. The researchers did not give any treatment to the participant so the result was drawn originally. This is what we called descriptive study [19].

\section{A. Participant}

This study includes data collection from teachers and students. They are convenience samples. Convenience sampling is a group of individuals who (conveniently) are available for study [9].

We have eight teachers sample who take science education at post graduate program. They have different educational background, such as chemistry education (3 teachers), physics education (3 teachers), and biology ( 2 teachers). Meanwhile, the sample students are 42 students of junior high school at $8^{\text {th }}$ grade.

\section{B. Data Collection and Data Analysis}

As has been mentioned before, we have 14 questions of questionnaire to draw teacher's profile in designing their goals, the concept which will be applied, pedagogical aspects in teaching particular material, evaluation element, and the 
methods in developing students' reasoning skill. Then we evaluated and classified them into 3 level, they are; pre PCK, growing PCK, and mature PCK. The rubric is adopted from Anwar [2]. Finally we could conclude which level the teacher is. Further, we also assess the readability of question.

The topic of reasoning test was environment pollution. It was essay questions which demandedanswer, data, and reason. There are 12 essay questions about environmental pollution. We used the rubric to assess the reasoning skill by giving score 1 until 5 as same as their arguments level. Then we use Anates ver. 4.0.5 software. We focused on reliability test and correlation significances and took the item test with very significant or significant level.

\section{RESULTS AND DISCUSSION} in turn.

In reporting our findings, we revisit our research question

\section{A. Teacher's PCK about Reasoning Development}

Before giving the questionnaire to the teacher, we had ensured the readability of the question. This step was done to prevent the data from becoming bias caused by misinterpretation. First, the five aspects of PCK were carefully analysed. They are about learning goal, concept, pedagogical knowledge, evaluation, and reasoning development.

Question about teacher's profile in designing their goals has very good readability $(100 \%)$, concept mastery which will be applied has very good readability (100\%), pedagogical aspects in teaching particular material has very good readability $(100 \%)$, assessment has very good readability $(100 \%)$, and the methods in developing students' reasoning skill has very good readability $(100 \%)$. Although all of the readability is $100 \%$, we have to guide teacher to fill the questionnaire. We had to do interview as well. Here are questions;

1. What do you intend students to learn about environmental pollution?

2. Why is it important for students to know this idea or concept?

3. What else do you know about this idea but you do not intend students to now yet?

4. What are difficulties for teaching this idea?

5. What are the student's conditions that influence you to teach this idea (such as prior knowledge / wrong concept that are probably found in teaching this idea)?

6. What are others factors that influence you to teach this idea?

7. How do you teach this idea to your students?

8. How do you ascertain students' understanding or confusion about this idea?

9. How do you optimize available media or technology to support your teaching?

10. How do you anticipate the lack facilities at your school in teaching this idea?
11. What is the importance of students' reasoning skill for you?

12. Have you applied and developed reasoning activities for students at your class?

13. How do you integrate reasoning activities with science learning?

14. How do you assess the reasoning skill of your students about this concept?

Besides the questionnaire, we also conducted interviews. There are a number of reasons to conduct interview. First, teachers could feel free to deliver their idea orally. They could complete their answer directly. For most teachers, aninterview is better than a written questionnaire. In the following part, we presents a description of teachers' PCK based on their background of education.

1) $A A Y$ and ISE (Biology Education Background)

We examined the PCK profile from 5 aspects; learning goal, concept mastery, pedagogical mastery, evaluation, and development students' reasoning skill.

\section{a) Learning Goal}

AAY and ISE are teachers in the high school which applies 2006 curriculum. They identified basic competence that is related to environmental pollution. They have logical consideration how to mix the learning material with learning strategy, hence they could draw competence target and determine the concept related to the general topic.

AAY did not only focus on the kinds of pollution but also the interaction of biotic and abiotic factors in ecosystem. She took the reference from basic competence 3.8 (interaction of biotic and abiotic factors in ecosystem) and 3.9 (pollution and its effects). She argued that human life has the great roles to create pollution. On the contrary, ISE focusedon types of pollution. She could mention her target that is related to basic competence 3.9 , but she did not consider the concept that is needed by student in order to solve the pollution. Their abilities in designing learning goals and deliver the conceptare on growing level.

\section{b) Concept Mastery}

Most of their answers show that they would deliver types of pollution such as air, water, and land pollution to their students. They knew which concept should be delivered. They were aware that they would find misconception or wrong concept from students' answer, so they prepared the way to minimalize them. They deserve for growing level of PCK on concept mastery.

AAY delivered the idea about biotic and abiotic factors in ecosystem and also kinds of pollution. She restricted the concept and did not explain the concept of $\mathrm{pH}$ (soil quality) and viscosity. She knew that explaining the $\mathrm{pH}$ and viscosity was very complex for her students. She noticed that her students could not differentiate the ozone hole and greenhouse effect. They will be misconception.

ISE planned to deliver the matter about types, causes, and effects of pollution, especially the air pollution. They are 
related to core concept of pollution based on basic competence. She could determine the limit of topic that should be delivered to students. She did not deliver the reaction of greenhouse gasses to her students because her students have not learned it. She only highlighted the greenhouse gasses produced by fuel combustion. She warned her students to minimize fuel combustion in their real life. She could predictmis conception of this topic which was about relation of global warming and greenhouse effect, ozone hole, and its effect.

\section{c) Pedagogical Mastery}

AAY and ISE had many considerations for choosing learning strategies. They adapted learning strategies based on characteristics of topic, facilities or media, and sequences on the book. Both of the mare on growing level of PCK.

AAY believed that problem-based learning was the proper model to teach environmental pollution. She optimized the facility around her. She planned to face her student to the real situation or use projector to show up the phenomenon. Finally, she asked her students to propose solutions.

ISE would use the video to show up environmental pollution. She planned to conduct discussion in the class. She asked students not only to propose the solutions but also make the paper. She was aware that her school has many restrict facilities so she asked her student to find information from the internet.

\section{d) Assessment}

ISE said that she would conduct oral test to measure her students' understanding. But she explained more than it should be. On the other hand, AAY used essay test. Both of them, used essay test to assessstudent's understanding. They argued that essay test could be proper understanding parameter because it could prevent students from guessing the answer. So, they deserve to get growing level of PCK.

\section{e) Developing Students' Reasoning Skill}

AAY and ISE did not integrate reasoning activities into teaching-learning activity. However, both of them agreed that reasoning skill is very important for students. If AAY had an opportunity, she would give an essay test with specific rubric. Those questions will be problem oriented. Meanwhile, ISE could not differentiate reasoning activities and general discussion. She was sure that using audio visual media would help student to reach reasoning skill. It is impossible to shape student with good reasoning skill with those ways. They deserve get pre PCK level for development of students' reasoning skill.

2) MAR, MYU, and AAM (Physics Education Background)

We examined the PCK profile from 5 aspects; learning goal, concept mastery, pedagogical mastery, assessment, and developing students' reasoning skill.

\section{a) Learning Goal}

Generally MAR, MY, and AAM could mix and match the concept with the demand of the curriculum. They have been teaching for several years. They could describe what they are going to deliver in the class related to the concept, because of that they deserve to get growing level of learning goal.

MAR used the precriptive competence to formulate the learning goal. She wanted her students to have capability in describing types of pollution, causes, and solutions. MY and AAM also did the same with MAR. They focused to this basic competence. They could develop certain indicator to measure their learning target. But they did not consider others factors such as analysis need of students, or environmental urgency.

\section{b) Concept Mastery}

MAR is on growing level of concept mastery. She could mention the idea that is related to the general topic. She had many profiles of students' misconceptions and planned to reduce them. MAR told researcher that she would not deliver students with pollution gasses such as $\mathrm{SO}_{2}$ or $\mathrm{SO}_{3}$ and its reaction and also ozone composition. She found difficulties to explain those gasses because they are abstract. She always introduces those gasses by using picture and a brief explanation. In other case, the student of $7^{\text {th }}$ grade hasn't studied the atmosphere composition yet. So, these will be very hard for them. She also found that the students' understanding of global warming and ozone hole are mistaken. They could not explain differences both of them.

MY could mention the idea of environmental pollution, but he could not give restriction of those concepts, which ones should be delivered. He could not predict and find the misconception from those concepts. He deserves get pre PCK level for his concept mastery. AAM also deserves get pre PCK level for concept mastery. He could mention ideas but he could not draw difficulties in teaching these concepts. He was confused, what kinds of misconception would appear in the class.He could not mention misconceptions because he does notteach the $7^{\text {th }}$ grade, but it is not a reason. As a professional teacher, he has to master all of science content knowledge.

\section{c) Pedagogical Mastery}

Their pedagogical mastery is on growing level. They did not only follow the book guidance how to teach but also analyze the topic. Before commencing the lesson, they checked facilities such as media. They used it as consideration of learning strategies.

MAR's school does not have electricity installation, but she used her surrounding environmental as an object learning, for example observing the rubbish on the water canal or showing the picture on newspaper. She developed students' responsibility to reduce and recycle rubbish. MYU and AAM also planned to show environmental pollution by using pictures. They would visit dirty water canal if they could notplay the video by using projector in the class.

\section{d) Assessment}

MAR, MYU, and AAM used essay test to assess students' understanding. Three of them deserve to get growing PCK level on evaluation. Besides, MAR and MY gave project task to recycle rubbish. This project aimed to rise up students' responsibility of environmental pollution. 
e) Developing Students' Reasoning Skill

AAM hasn't developed reasoning skill of students, but he planned to give a contextual problem to her students. He would give essay to his students. He deserves to get pre PCK level for development of students' reasoning skill.

MY and MAR argued that reasoning kill is very important for student because it could enhance cognitive skill and learning quality of students. They used video or texts to show the environmental problems to their students, and later they conducted discussion. Unfortunately they did not know how to measure the quality of students' argumentation on discussion. They deserve to get growing level for development of students' reasoning skill.

\section{B. TQO, RYE, and HEL (Chemistry Education Background)}

We examined the PCK profile from 5 aspects; learning goal aspect, concept aspect, pedagogical aspects, evaluation aspects, and development students' reasoning skill.

\section{1) Learning Goal}

TQO, RYE, and HEL have good abilities in designing their learning goals to deliver the concept. It is on growing level. They know what, why, when, and how to mix and match concept with basic competence of curriculum.

RYE and HEL were not only focus on types of pollution but also the interaction of human life with environment. On the other hand, TQO was only focus on factors that caused pollution. He argued that he only had a little time to deliver these topics but he could deliver it well.

\section{2) Concept Mastery}

TQO, RYE, and HEL could choose the concepts properly which are related to the major topic of environmental pollution. They could predict what kinds of misconception or wrong concept would appear. So they deserve get growing level of concept mastery.

HEL would not explain the chemical reaction to her students. She only explained human and its habits on producing greenhouse gasses, such as carbon monoxide or carbon dioxide. She also could predict misconceptions about global warming and greenhouse effect. TQO and RYE did the similar actions. They knew that global warming and greenhouse effect would create misconception.

\section{3) Pedagogical Mastery}

In choosing learning strategies, they did not only consider the learning package material on the book but also analysis of the needs, basic competence, and supported facilities. They deserve to get growing level of pedagogy mastery.

TQO planned to conduct discussion in his class. He would guide his students to produce conclusion. He used projector or picture to show pollution phenomenon. Whereas, HEL would apply problem based learning model at her class. She would start the class by giving the story of environmental pollution. Then, she would guide her students on discussion. Meanwhile, RYE did not tell specific model to teach these topics. She only wanted her students to know the pollution. She faced her students to the real situation that earth is on danger caused by pollution. She expected her students to conduct discussion. Videos and pictures were the media for her learning strategies.

\section{4) Assessment}

TQU used multiple choice questions to assess his students' understanding. He deserves toget pre level of evaluation aspect. RYE and HEL were more creative than TQU. They used essay test because it could measure students' thinking skill.HEL did not only consider the answer but also data and reason that supported the answer. Thus, they deserve to get growing level for evaluation aspect.

\section{5) Developing Students' Reasoning Skill}

TQO and RYE haven't applied reasoning activities on their learning. Both of them argued that reasoning skill is very important for their students. TQO and RYE planned to apply problem based learning model at their class. They deserve to get pre level of reasoning development.

HEL deservesto get growing level for reasoning development aspect. She tried to integrate reasoning skill to the learning through discussion. She forced student to fulfill the answer with data and reason.

\section{Students'Reasoning Skill}

We have informed that we used Anates Ver. 4.0.5software to check the validity. We got data such as reliability, significance, and level of difficulties. We could see the complete data on table 3 above.

Based on the table 3, it can be seen that the reliability is 0.74. Reliability is a constant instrument in evaluating what are being evaluated. It means that whenever that instrument is used, it will show the relatively same result [18]. Reliability test is conducted to find the accuracy of evaluation tools in measuring students' accuracy in answering the exam once they did it. We see that questions number 5, 7, 11, and 12 are not significant. Based on those reasons, we conducted interview with some of students to gain clear explanation.

TABLE II. VALIDITY OF TEST

\begin{tabular}{|c|c|c|c|}
\hline \multicolumn{2}{|c|}{ Average Score } & \multicolumn{2}{|l|}{24.83} \\
\hline \multicolumn{2}{|c|}{ Deviation Standard } & \multicolumn{2}{|l|}{5.31} \\
\hline \multicolumn{2}{|c|}{ Correlation XY } & \multicolumn{2}{|l|}{0.58} \\
\hline \multicolumn{2}{|c|}{ Test Reliability } & \multicolumn{2}{|l|}{0.74} \\
\hline \multicolumn{2}{|c|}{ Number of Question } & \multicolumn{2}{|l|}{12} \\
\hline \multicolumn{2}{|c|}{ Number of Students } & \multicolumn{2}{|l|}{42} \\
\hline $\begin{array}{c}\text { No. } \\
\text { Question }\end{array}$ & Correlation & Significance & $\begin{array}{c}\text { Level of } \\
\text { Difficulties }\end{array}$ \\
\hline 1 & 0.644 & very significant & Medium \\
\hline 2 & 0.606 & very significant & Medium \\
\hline 3 & 0.756 & very significant & Medium \\
\hline 4 & 0.543 & Significant & Medium \\
\hline 5 & 0.214 & - & Medium \\
\hline 6 & 0.626 & very significant & Medium \\
\hline 7 & 0.477 & - & Medium \\
\hline 8 & 0.522 & Significant & Medium \\
\hline 9 & 0.536 & Significant & Medium \\
\hline 10 & 0.641 & very significant & Medium \\
\hline 11 & 0.360 & - & Difficult \\
\hline 12 & 0.402 & - & Difficult \\
\hline
\end{tabular}

Question number 5 is about water pollution. Students did not have enough knowledge, how does chemicals on the bubble of soap and detergent harmful septic tank decomposer. 
They argued that chemical waste from soap and detergent will disappear in the water. Number 7 is also about water pollution. Students got difficulties how to differentiate the sources of E.coli. Some of them did not know how E.coliappears.

Number 11 and 12 are about air pollution. Students did not know the haze from kerosene and LPG combustion. They argued both of them were same. The issue about AC could not initiate them to give argument logically because they missed the concepts. They had to learn the basic concept of global warming and ozone hole, so they could give logic argumentation.

We also count number of argumentation. We could not find argumentation at level 5. The highest level was four. Students could complete argument with claim, data, backing, and qualifier. But they could not give any rebuttal. They were focus to their answer without giving rebuttal. This was because of lack knowledge or information. Here is the percentage of argumentation level on the table 3 .

TABLE III. STUdENTS’ ARgUMENTATION

\begin{tabular}{|c|c|c|c|c|c|c|c|}
\hline \multirow[b]{2}{*}{ No } & \multirow[b]{2}{*}{ Topic } & \multirow[b]{2}{*}{ No } & \multicolumn{5}{|c|}{ Number of Arguments (\%) } \\
\hline & & & $\begin{array}{c}\text { Level } \\
1\end{array}$ & $\begin{array}{c}\text { Level } \\
2\end{array}$ & $\begin{array}{c}\text { Level } \\
3\end{array}$ & $\begin{array}{c}\text { Level } \\
4\end{array}$ & $\begin{array}{c}\text { Level } \\
5\end{array}$ \\
\hline \multirow{4}{*}{1} & \multirow{4}{*}{$\begin{array}{l}\text { Land } \\
\text { Pollution }\end{array}$} & 1 & 33.33 & 11.90 & 28.57 & 26.19 & 0 \\
\hline & & 2 & 16.67 & 33.33 & 45.24 & 4.76 & 0 \\
\hline & & 3 & 16.67 & 35.71 & 45.24 & 2.38 & 0 \\
\hline & & 4 & 19.05 & 16.67 & 64.29 & $0 \%$ & 0 \\
\hline \multirow{4}{*}{2} & \multirow{4}{*}{$\begin{array}{l}\text { Water } \\
\text { Pollution }\end{array}$} & 5 & 42.86 & 38.10 & 21.43 & $0 \%$ & 0 \\
\hline & & 6 & 21.43 & 26.19 & 52.38 & $0 \%$ & 0 \\
\hline & & 7 & 35.71 & 30.95 & 30.95 & 2.38 & 0 \\
\hline & & 8 & 30.95 & 30.95 & 38.10 & $0 \%$ & 0 \\
\hline \multirow{4}{*}{3} & \multirow{4}{*}{$\begin{array}{l}\text { Air } \\
\text { Pollution }\end{array}$} & 9 & 9.52 & 57.14 & 33.33 & $0 \%$ & 0 \\
\hline & & 10 & 19.05 & 28.57 & 52.38 & $0 \%$ & 0 \\
\hline & & 11 & 73.81 & 14.29 & 11.90 & $0 \%$ & 0 \\
\hline & & 12 & 69.05 & 21.42 & 9.52 & $0 \%$ & 0 \\
\hline
\end{tabular}

\section{Discussion}

Generally, most of science teachers in Indonesia have specific background of education such as biology, physics, and chemistry. When we knew that the sample of our research, we were afraid that teacher would answer the questionnaire based on their education perspective. But fortunately, they were able to choose the concept based on the curriculum demands. They did not have tendencies to deliver the concept of pollution based on their personal perspective. They gave the proper portion on the concepts. They combined and integrated biology, chemistry, and physics in a topic named environmental pollution. All of questions of $\mathrm{CoRe}$ about reasoning development could be answered well although they had different educational background.

Based on teachers' answer, they planned to deliver concepts about the types of pollution. Unfortunately, only several of them who gave clear explanation about it. When we gave some follow-up questions to them, what kind of pollution and why, they replied with air pollution such as global warming and greenhouse effect. Most of them neglected the common pollution such as plastic rubbish or water crisis. Therefore, we needed detail interviews to investigate and dig more information from them, why the idea of global warming was so dominant than others. On the other hands, rubbish endangers theenvironment. Itcan impact water and land quality badly. There is so much toxic when people burn rubbish or use detergent, but the teacher did not notice these.

Several teachers argued that discussion was able to enhance reasoning skill of students. Discussion forces student to argue and to deliver comment related to the topic. Unfortunately, they did not explain how they conduct discussion. Every model of science learning such as problem based learning or inquiry need discussion as the elaboration process to shape reasoning skill of students. We need a model of discussion.

Based on those points above, while doing interview, we had to ask the objectives of discussion, what kind of issue would be delivered, what kind of method would be used, how does teacher propose the question in discussion, how does teacher adopt discussion for various students, how does teacher enlarge students' argumentation in discussion, and how does teacher set the class during discussion[3].

\section{CONCLUSION}

Based on the analyses of the data we conclude that the modified CoRe can be used to collect data on teacher PCK. Those questions could describe teacher's PCK about reasoning development of students. Reasoning skill is measured by argument completeness. Further, the try-out result shows the reliability is 0.74 and we can use 8 questions from 12 questions about environmental pollution.

\section{References}

[1] Adadan, E \& Oner, D. (2014). Exploring the Progression in Preservice Chemistry Teachers' Pedagogical Content Knowledge Representations: The Case of "Behavior of Gases. Research Science Education. 44, (6), 829-7858

[2] Anwar , Y. (2014). Perkembangan Pedagogical Content Knowledge (PCK) Calon Guru BiologipadaPesertaPendekatanKonsekuentifdanpadaPesertaPendekatan Konruen.Disertasi, SekolahPascaSarjana, UniversitasPendidikan Indonesia.

[3] Arends, Richard. (2008). Learning to Teach.New York: McGraw Hill Companies

[4] Aydin, S., Demirdogen, B., Akin, F.N., Kondacki, E.U., Tarkin, A. (2015). The Nature and Development of Interaction among Components of Pedagogical Content Knowledge in Practicum. Teaching and Teacher Education. 46, 37-50.

[5] Bekiroglu, F.O. and Eskin, H. (2012). Examination of The Relationship Between Engagement in Scientific Argumentation and Conceptua Knowledge. International Journal of Science and Mathematics Education. 10, (6), 1415-1443.

[6] Bektas, O, et al. (2013). Pre-Service Chemistry Teachers' Pedagogical Content Knowledge of The Nature of Science in The Particle Nature of Matter. Chemical Education Research and Practice. 14, (2), 201-213.

[7] Bertram, A \& Loughran, J. (2012). Science Teacher's Views on CoRes and PaP-eRs as a framework for Articulating and Developing Pedagogical Content Knowledge. Research Science Education. 42, 1027-1047.

[8] Faikhamta, C. and Clarke, A. (2013). A Self Study of a Thai Teacher Educator Developing a Better Understanding of PCK for Teaching about Teaching Science. Research Science Education. 43, (3), 955 -979.

[9] Fraenkel, J.R., Wallen, N.E., and Hyun, H.H. (2012). How to Design and Evaluate Research in Education. New York : McGraw-Hill. 
[10] Herawati, Desti. (2015). PenalaranIlmiah (Scientific Reasoning) SiswaSekolahBerorientasiLingkungandanSekolahMultinasional. Tesis. Bandung: UniversitasPendidikan Indonesia.

[11] Hume, A and Berry, A. (2011). Constructing CoRes- a Strategy for Building PCK in pre-service Science Teacher Education. Research Science Education. 41, 341-355.

[12] Hume, A and Berry, A. (2013). Enhancing the Practicum Experience for Pre-service Chemistry Teachers Through Collaborative CoRe Design with Mentor Teachers. Research Science Education. 43, 2107-2136.

[13] Kurniadi, A., Widodo, A., Rochintaniawati, D., and Riandi. (2015). Analisis Reasoning Skill Siswa pada Pembelajaran Biologi SMA Prosiding Simposium Nasional Inovasi dan Pembelajaran Sains 2015. 237-240.

[14] Lazonder, A.W., and Drost, S.W. (2014). Advancing Scientific Reasoning in Upper Elementary Classroom: Direct Instruction VersusTast Structuring. Journal of Science Education and Technology.

[15] Loughran, J., Berry, A., and Mulhall, P. (2012). Understanding and Developing Science Teacher's Pedagogic Content Knowledge.Clayton :Monash University.

[16] Nilsson, P \& Loughran, J. (2012). Exploring Interaction among Components of Pedagogical Content Knowledge in Practicum. the Development of Pre-Service Science Elementary Teachers' Pedagogical Content Knowledge. Science Teacher Education. 23, 699-721

[17] Sampson, V., Grooms, J., Walker, J.P. (2011). Argument-Driven Inquiry as a Way to Help Students Learn How to Participate in Scientific Argumentation and Craft Written Arguments: An Exploratory Study. Science Education. 95, (2), 217-257.

[18] Sugiyono. (2011). MetodePenelitianPendidikan. Bandung: Alfabeta.

[19] Sukmadinata, N.S. (2009). MetodePenelitianPendidikan. Bandung : PT RemajaRosdakarya.

[20] Sutopo and Waldrip, B. (2014). Impact of A Representational Approach on Students' Reasoning and Conceptual Understanding in Learning Mechanics. International Journal of Science and Mathematics, 12, 741 765 .

[21] Williams, J., Eames C., Hume, A and Lockley, J. (2012). Promoting Pedagogical Content Knowledge Development for Early Career Secondary Teachers in Science and Technology Using Content Representations. Research in Science \& Technological Education. 30 (3), 327-343. 